\title{
Performance of Concrete Beams Reinforced with GFRP Bars
}

\author{
Sungwoo Shin ${ }^{1}$, Daewon Seo*2 and Byumseok $\operatorname{Han}^{3}$ \\ ${ }^{1}$ Professor, Department of Architectural Engineering, Hanyang University, Korea \\ ${ }^{2}$ Graduate Student, Department of Architectural Engineering, Hanyang University, Korea \\ ${ }^{3}$ Technology Advisory Division, Dongbu Corporation, Korea
}

\begin{abstract}
The strengthening of reinforced concrete structures using advanced fiber reinforced polymer (FRP) composites is a very popular practice because they are light and highly resistant to corrosion. In particular, the behavior of FRP-reinforced concrete structures is a topic that attracted lot of interest in recent years. However, the application of FRP-reinforced concrete structures requires an extensive development of reliable design equations.

This study focuses on the behavior of beams reinforced with different reinforcement ratios of glass fiber reinforced polymer (GFRP) bars and concrete strength. Displacement, strains, and crack width were measured to study the behavior of beams. The results of the investigation can be summarized as follows: (1) Deflections and strains of concrete beams reinforced with GFRP re-bars are generally larger than those reinforced with steel bars; (2) the strength of the concrete has a negligible effect on crack spacing and crack width; (3) and the FRP over-reinforced concrete beams in this study are safe for design in terms of deformability.
\end{abstract}

Keywords: fiber reinforced polymer (FRP); concrete beams; FRP bars; flexural behavior

\section{Introduction}

The corrosion of steel reinforcements is one of the major problems that shorten the lifetime serviceability of concrete structures. There are many existing methods to prevent, delay, or repair the deterioration of concrete structures due to the corrosion of steel reinforcements. Examples include decreasing concrete porosity, coating steel bars with a protective epoxy, increasing reinforcement cover requirements, and taking cathodic protection measures. However, these methods are costly and their long-term effectiveness is uncertain.

Many researchers now view fiber reinforced polymer (FRP) bars as an efficient and economical method to overcome the corrosion problems inherent to steel rebars in harsh environments. Fiber reinforced polymers (FRP) are a good alternative to steel because they are strong and highly resistant to corrosion. FRP reinforcements have a high strength to weight ratio, good fatigue properties, and electromagnetic resistance (Rasheed et al. 2003, Abdalla 2002, Toutanji et al.

*Contact Author: Daewon Seo, Graduate Student, Department of Architectural Engineering, Hanyang University, 1271 Sa-3 dong, Sangnok-gu, Ansan, Kyeonggi-do, Korea Tel: +82-31-400-5132 Fax: +82-2-6280-2808

E-mail: dwseo@hanyang.ac.kr

(Received October 8, 2008 ; accepted January 21, 2009)
2002, Toutanji et al. 2000, Masmoudi et al. 1998).

In Korea, however, FRPs are used only to strengthen deficient reinforced concrete structures. The major obstacles are the low modulus of elasticity, the low ductility in comparison to steel bars, and the absence of design guidelines. Hence, there is a need for suitable design guidelines and for methods that reliably estimate the behavior of members that are reinforced with FRP.

Research projects in Korea have been carried out to develop the FRP internal reinforcement for concrete structures (KICT 2004). This paper presents the behavior of concrete beams reinforced with glass FRP (GFRP) bars.

\section{Research Significance}

This paper presents the experimental results of testing concrete beams reinforced with GFRP bars under static loading conditions up to failure. This study investigates various behaviors including crack pattern and width, deflections, strains, and modes of failure. The behavior of concrete beams reinforced with GFRP bars is compared with the behavior of beams reinforced with steel. This study focuses on the effects of concrete strength and the reinforcement ratio on the behavior of concrete beams.

This study also aims to provide engineers and researchers with a better understanding of the behavior 
of GFRP-reinforced concrete beams. The results obtained throughout this study are valuable for future field applications and the development of design guidelines for concrete elements reinforced with FRP bars.

\section{Experimental Program}

\subsection{Material Characteristics}

Table 1 . shows the material properties of the reinforcement materials. Both FB and HFB beams are constructed using pre-mixed concrete provided by a local supplier. The target compressive strengths of the concrete after 28 days are 30 and $50 \mathrm{MPa}$ for $\mathrm{FB}$ and HFB, respectively. Six concrete cylinders are tested in compression after 28 days. The average compressive strengths of the FB cylinders and the corresponding HFB cylinders are $34 \mathrm{MPa}$ and $45 \mathrm{MPa}$, respectively.

The GFRP bars are manufactured by the pultrusion of E-glass continuous fibers and thermosetting polyester resin. To improve the bond characteristics of the bars, their surfaces are wrapped with helical glass fiber strands (Fig.1.). The GFRP bars used in this study are $12.7 \mathrm{~mm}$ in diameter.

The tensile strength and modulus of elasticity of the GFRP bars are $690 \mathrm{MPa}$ and $41 \mathrm{GPa}$, respectively. The yield stress of the longitudinal reinforcing steel is 400 $\mathrm{MPa}$, while the yield stress of the stirrups steel is 460 $\mathrm{MPa}$.

\subsection{Test Specimens}

Fig.2. shows details of the test specimens. Table 2. provides the designations of beams and the

Table 1. Characteristics of Reinforcements

\begin{tabular}{ccccc}
\hline & $\begin{array}{c}\text { Diameter } \\
(\mathrm{mm})\end{array}$ & $\begin{array}{c}\text { Modulus of } \\
\text { elasticity } \\
(\mathrm{GPa})\end{array}$ & $\begin{array}{c}\text { Yielding } \\
\text { Strength } \\
(\mathrm{MPa})\end{array}$ & $\begin{array}{c}\text { Tensile } \\
\text { Strength } \\
(\mathrm{MPa})\end{array}$ \\
\hline \multirow{3}{*}{ Steel } & 10 & 200 & 460 & 560 \\
\cline { 2 - 5 } & 16 & 200 & 410 & 540 \\
\hline GFRP & 13 & 200 & 400 & 560 \\
\hline
\end{tabular}

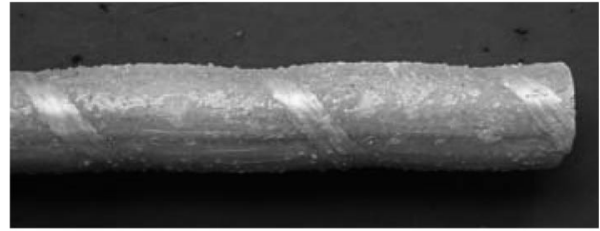

Fig.1. Glass FRP Bars

characteristics of longitudinal reinforcement and concrete. The beams are $300 \mathrm{~mm}$ wide, $400 \mathrm{~mm}$ deep, and 4,000 $\mathrm{mm}$ long. The shear span remains constant at $1,200 \mathrm{~mm}$ for all tests, providing a shear span-todepth ratio of 3.4. A concrete clear cover of $30 \mathrm{~mm}$ is maintained for all of the tested beams.

Two concrete strength ratios and five GFRP reinforcement ratios are used in the study for a total of 10 different specimens. For comparison, two concrete beams with conventional steel bars are tested as the control specimens. The GFRP reinforcement ratios are chosen to represent both under-reinforced and overreinforced conditions. Due to the unavailability of GFRP stirrups, $9.53 \mathrm{~mm}$ diameter steel bars are used as stirrups for shear reinforcement.

The balanced design reinforcement ratio $\rho_{f b}$ produces balanced strain conditions and is calculated by Eq.(1)(ACI committee 440 2006).

$$
\rho_{f b}=\frac{0.85 \beta f_{c}^{\prime}}{f_{f u}}\left(\frac{0.003 E_{f}}{0.003 E_{f}+f_{f u}}\right)
$$

where $\beta$ is the ratio of the depth of the equivalent rectangular stress block to the depth of the neutral axis, $f_{c}^{\prime}$ is the compressive strength of the concrete, $f_{f u}$ is the ultimate strength of the FRP bars, and $E_{f u}$ is the modulus of elasticity of the FRP bars. Table 2 . shows the values of $\rho_{f b}$ for the beams tested in this study.

The beams receive a designation of $\mathrm{S}$ or $\mathrm{F}$, referring to the two types of reinforcement used: steel or glass FRP bars. The letter $\mathrm{H}$ indicates the high-strength concrete. The numbers indicate the number of bars in the longitudinal reinforcement.

Table 2. Parameters of Tested Beams

\begin{tabular}{|c|c|c|c|c|c|c|c|}
\hline Specimens & $\begin{array}{c}\text { Reinforcement } \\
\text { material }\end{array}$ & $\begin{array}{c}f_{c}^{\prime} \\
(\mathrm{MPa}) \\
\end{array}$ & $\mathrm{a} / \mathrm{d}$ & $\rho$ & $\rho / \rho_{\mathrm{b}}$ & $\begin{array}{c}\text { Overall depth } \\
\mathrm{h}(\mathrm{mm})\end{array}$ & $\begin{array}{l}\text { Width } \\
\mathrm{b}(\mathrm{mm}) \\
\end{array}$ \\
\hline SB-2 & \multirow{2}{*}{ steel } & 30 & \multirow{2}{*}{3.4} & 0.73 & 0.2 & \multirow{2}{*}{40} & \multirow{2}{*}{30} \\
\hline HSB-3 & & 50 & & 1.09 & 0.25 & & \\
\hline FB-2 & \multirow{5}{*}{ GFRP } & \multirow{5}{*}{30} & \multirow{5}{*}{3.4} & 0.24 & 0.46 & \multirow{5}{*}{40} & \multirow{5}{*}{30} \\
\hline FB-3 & & & & 0.36 & 0.70 & & \\
\hline FB-4 & & & & 0.48 & 0.93 & & \\
\hline FB-6 & & & & 0.72 & 1.39 & & \\
\hline FB-8 & & & & 0.96 & 1.86 & & \\
\hline HFB-3 & & \multirow{5}{*}{50} & \multirow{5}{*}{3.4} & 0.36 & 0.57 & \multirow{5}{*}{40} & \multirow{5}{*}{30} \\
\hline HFB-4 & & & & 0.48 & 0.76 & & \\
\hline HFB-6 & & & & 0.72 & 1.14 & & \\
\hline HFB-8 & & & & 0.96 & 1.51 & & \\
\hline HFB-10 & & & & 1.27 & 2.00 & & \\
\hline
\end{tabular}




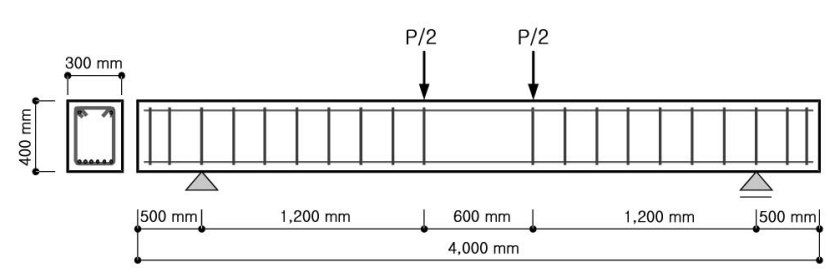

Fig.2. Details of Specimens (unit: $\mathrm{mm}$ )

\subsection{Test Setup and Test Procedure}

Fig.3. shows a schematic view of the test set-up. The beams with clear spans of $3000 \mathrm{~mm}$ are simply supported and subjected to four-point flexural testing, as shown in Fig.2. The load is monotonically applied during testing at a stroke-controlled condition using a 10,000 kN U.T.M (Universal Test Machine).

Deflection of the tested beams is measured with a linear variable differential transformer at mid-span. All of the tested beams are equipped with strain gauges bonded on reinforcing bars. Also at mid-span, the concrete compression surface is equipped with four strain gauges to measure deformation. All data are collected using a data acquisition system and stored in a personal computer. During testing, cracks are marked and crack width is measured using a handheld microscope. Crack spacing is measured within the constant moment zone. Deflections, ultimate capacities, and failure modes are also investigated.

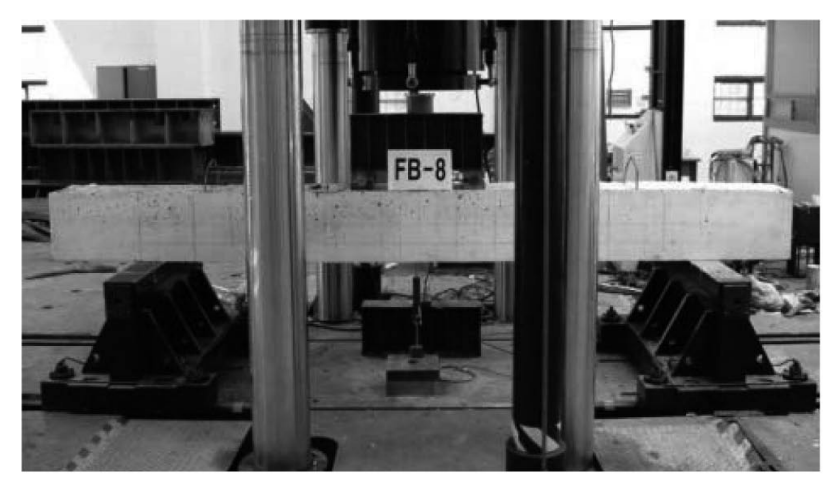

Fig.3. Test Setup

\section{Experimental Results and Discussion 4.1 General Behavior and Failure}

Table 3. presents the maximum load carried by each beam, $P_{\max }$ the deflection that corresponds to the maximum load, $\delta_{\max }$ and the modes of failure we observe in the tested beams.

The steel reinforced control beams (SB-2, HSB-3) develop flexural cracks at mid-span. After the first crack, flexural cracks are uniformly distributed throughout the tension zone. Following yielding of the steel bars, beam deflections increase without an increase in load. A ductile flexural failure occurs in SB-2 and HSB-3 with yielding of the reinforcing steel. The amount of energy absorbed through plastic deformation in the reinforcement demonstrates the advantage of steel as a reinforcing agent.

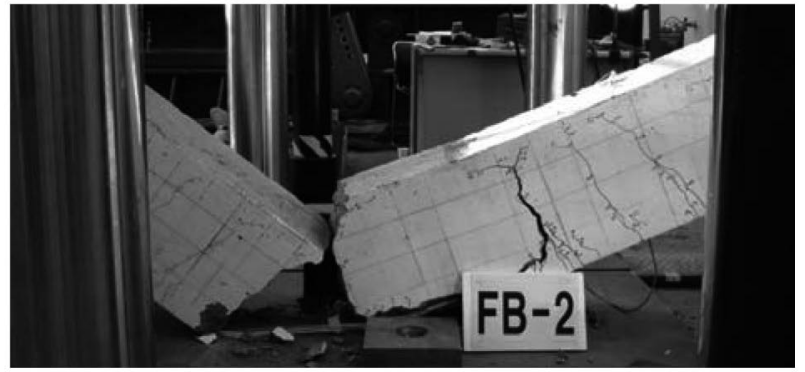

(a) Failure of FB-2 due to FRP Ruptures

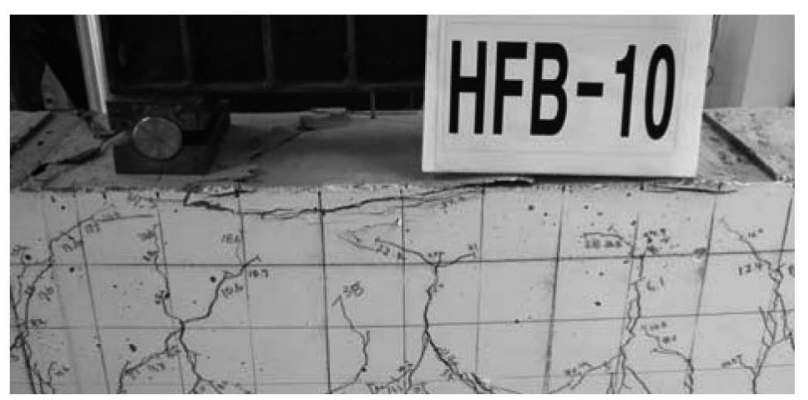

(b) Failure of HFB-10 due to Concrete Crushing

Fig.4. Typical Failure Mode of Beams Reinforced with GFRP Bars

Table 3. Failure Modes of Tested Beams

\begin{tabular}{ccccc}
\hline Specimens & $\rho / \rho_{\mathrm{b}}$ & $\begin{array}{c}\mathrm{P}_{\max } \\
(\mathrm{kN})\end{array}$ & $\begin{array}{c}\delta_{\max } \\
(\mathrm{mm})\end{array}$ & Failure Mode \\
\hline SB-2 & 0.2 & 256.6 & 44.5 & Flexural failure \\
HSB-3 & 0.25 & 340.7 & 47.8 & Flexural failure \\
FB-2 & 0.46 & 114.9 & 39.8 & FRP rupture \\
FB-3 & 0.70 & 185.3 & 45.3 & FRP rupture \\
FB-4 & 0.93 & 209.8 & 56.1 & FRP rupture \\
FB-6 & 1.39 & 285.9 & 53.3 & Concrete crushing \\
FB-8 & 1.86 & 371.0 & 63.0 & Concrete crushing \\
HFB-3 & 0.57 & 155.4 & 40.2 & FRP rupture \\
HFB-4 & 0.76 & 198.4 & 45.2 & FRP rupture \\
HFB-6 & 1.14 & 334.1 & 54.2 & FRP rupture/Bond failure \\
HFB-8 & 1.51 & 363.4 & 56.8 & Concrete crushing \\
HFB-10 & 2.00 & 365.6 & 43.0 & Concrete crushing \\
\hline
\end{tabular}

The behavior of the FRP reinforced beams differs from that of the steel reinforced beam. Final failure occurs in two distinctly different modes, as shown in Fig.4. The first mode is the FRP rupture of the underreinforced beams. Tensile rupture of the GFRP bar occurs in all beams that are reinforced with lower balanced reinforcement ratios (FB-2, FB-3, HFB-3, and HFB-4). These results demonstrate the brittleness of FRP materials.

The second mode of failure is the crushing of concrete in the over-reinforced beams. As expected, the failure in beams reinforced with more than the balanced reinforcement (FB-6, FB-8, HFB-8, and HFB-10) is due to the compressive failure of concrete 
crushing. Observed cracks within and near the constant moment region expand in a vertical direction. As the load increases, shear stress becomes more critical and induces inclined cracks. We observe similar characteristics of crack patterns for FB and HFB beams.

Table 4. shows the average crack spacing in tested beams at service load $\left(30 \% M_{u}\right)$ and high load $(90 \%$ $M_{u}$ ). The effect of the concrete strength and the reinforcement ratio on the crack spacing is negligible, and the crack spacing decreases as the load increases.

Table 4. Crack Characteristics of Beams

\begin{tabular}{|c|c|c|c|c|c|}
\hline \multirow[t]{2}{*}{ Beams } & \multirow{2}{*}{$\rho_{\mathrm{f}} / \rho_{\mathrm{fb}}$} & \multicolumn{2}{|c|}{$\begin{array}{l}\text { Average crack } \\
\text { spacing }(\mathrm{mm})\end{array}$} & \multicolumn{2}{|c|}{$\begin{array}{l}\text { Number of cracks } \\
\text { between point loads }\end{array}$} \\
\hline & & $30 \% \mathrm{M}_{u}$ & $90 \% \mathrm{M}_{u}$ & $30 \% \mathrm{M}_{u}$ & $90 \% \mathrm{M}_{u}$ \\
\hline SB-2 & 0.2 & 150 & 100 & 4 & 7 \\
\hline HSB-3 & 0.25 & 180 & 90 & 4 & 7 \\
\hline FB-2 & 0.46 & 300 & 200 & 2 & 3 \\
\hline FB-3 & 0.70 & 150 & 130 & 4 & 5 \\
\hline FB-4 & 0.93 & 110 & 100 & 5 & 6 \\
\hline FB-6 & 1.39 & 100 & 100 & 5 & 6 \\
\hline FB-8 & 1.86 & 130 & 150 & 4 & 6 \\
\hline HFB-3 & 0.57 & 100 & 90 & 5 & 6 \\
\hline HFB-4 & 0.76 & 90 & 60 & 6 & 7 \\
\hline HFB-6 & 1.14 & 90 & 70 & 5 & 8 \\
\hline HFB-8 & 1.51 & 100 & 40 & 5 & 10 \\
\hline HFB-10 & 2.00 & 100 & 50 & 5 & 8 \\
\hline
\end{tabular}

\subsection{Crack Width}

The crack width is an important parameter for measuring the structural performance of a reinforced concrete structure. The corrosion of steel is one of the reasons why controlling the width of cracks is important. Unlike in concrete structures reinforced with steel bars, the durability of concrete structures reinforced with GFRP bars is not critically dependent on the concrete crack width. Because concrete members reinforced with FRP bars in flexure possess significantly lower stiffness properties than members reinforced with steel bars, they may exhibit cracking that is excessive for the performance of structures in service. Thus, from the perspectives of aesthetics, serviceability requirements, and overall performance, the concrete crack width in an FRP-reinforced beam remains a serious concern. The ACI Committee 440 permits crack widths of 0.7 and $0.5 \mathrm{~mm}$ for interior and exterior exposure, respectively.

Fig.5. shows a comparison of the crack width measurement in the reinforced concrete beams at different load levels. These measurements show that the FRP reinforced beams generally have a larger crack width than the steel reinforced beam under the same applied loads, which is due to the low modulus of elasticity of GFRP bars.

Under the service load levels (in this paper, the service load is assumed to be about $30 \%$ of the ultimate load), the crack width decreases as the reinforcement ratio increases, and the crack width is only marginally

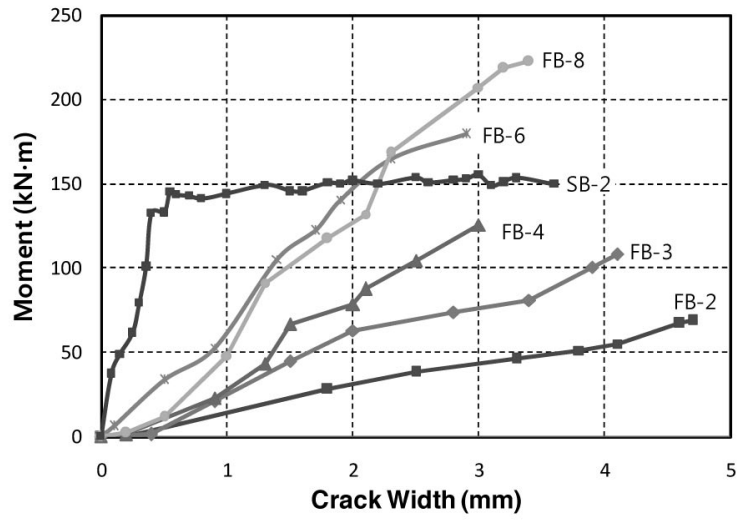

(a) SB and AFB Beams $\left(f_{c}^{\prime}=30 \mathrm{MPa}\right)$

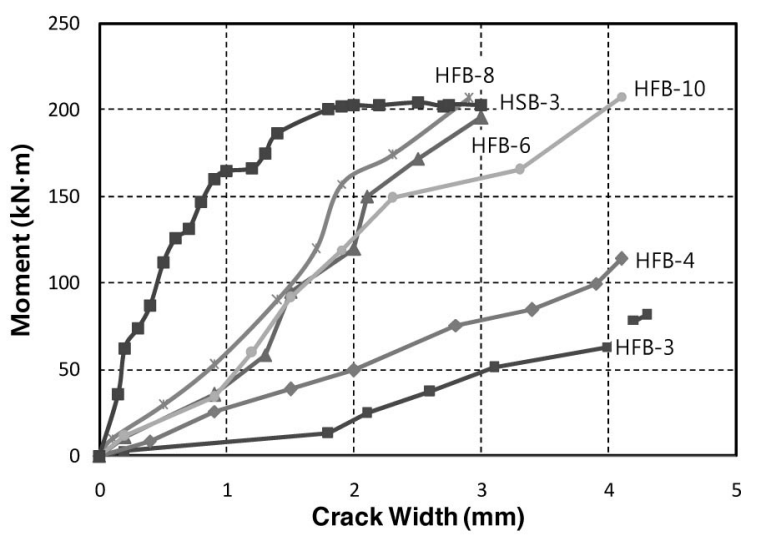

(b) HSB and HAFB Beams $\left(f_{c}^{\prime}=50 \mathrm{MPa}\right)$

Fig.5. Moment Versus Crack width of Beams

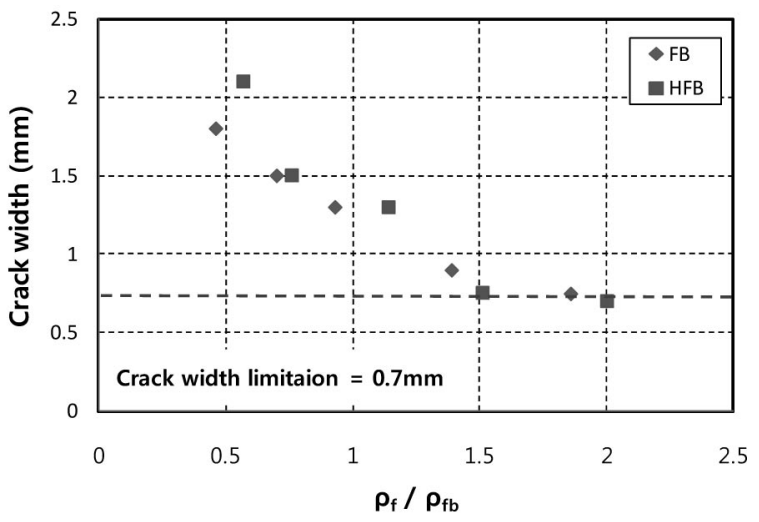

Fig.6. Crack Width Under Service Load

influenced by the concrete strength, as shown in Fig.6. This shows that the reinforcement ratio has a substantial effect on the crack width.

\subsection{Load and Deflection}

Each beam is tested under a static load until complete failure. The concrete beams reinforced with GFRP bars behave linearly up to cracking with reduced stiffness up to failure. After cracking, the results show a bilinear relationship. Fig.7. shows the comparison between beams reinforced with GFRP bars and beams reinforced with steel bars.

Beams of FB and HFB reinforced with GFRP bars do not crack where they exhibit linear load- 


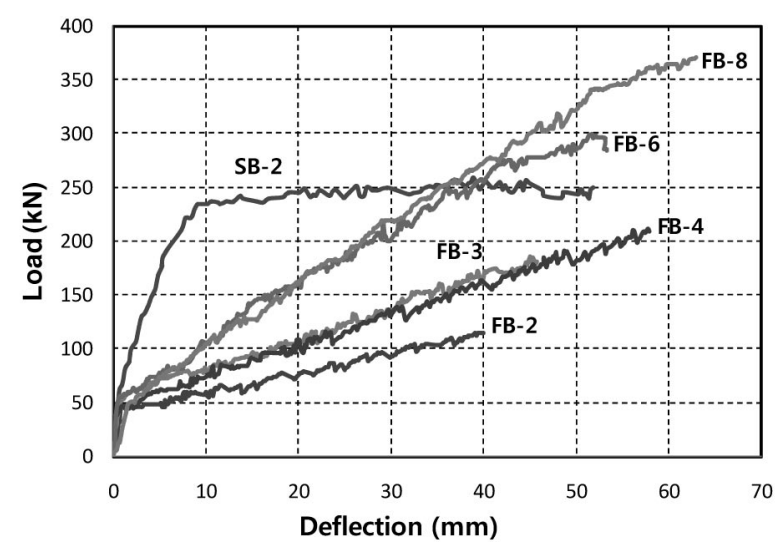

(a) SB and FB Beams $\left(f_{c}^{\prime}=30 \mathrm{MPa}\right)$

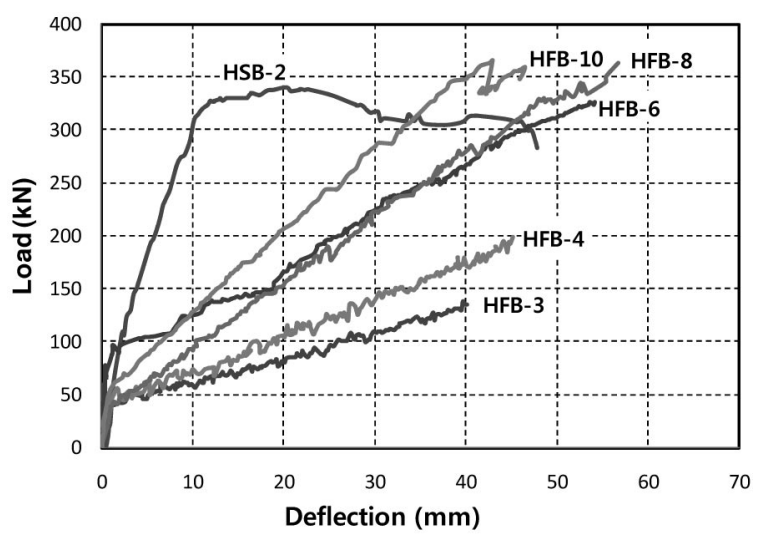

(b) HSB and HFB Beams $\left(f_{c}^{\prime}=50 \mathrm{MPa}\right)$

Fig.7. Load-deflection Relationship of Tested Beams

deflection behavior. This is attributable to the linear elastic characteristics of GFRP bars and concrete. With additional loading, cracking occurs at the moment zone when the applied load exceeds the cracking moment and causes a reduction in stiffness.

Fig.7. shows the effect of a low modulus of elasticity in reinforcement bars by the results of beams SB-2 and FB-6, which are reinforced with the same reinforcement ratio of steel and GFRP bars. The results show that after the first crack, the stiffness of SB-2 is not reduced as significantly as it is in the case of FB-6.

Fig.8. clearly shows the effects of the concrete strength and the reinforcement ratio. As the concrete strength and the reinforcement ratio increase, the ultimate flexural capacity increases. However, this increase is limited by the concrete failure strain. Similar remarks are made by Benmokrane (2004), who reports that the maximum moment capacity depends on the maximum concrete strain.

For a simply supported beam of span $\mathrm{L}$ that is loaded with two equal, concentrated loads $(\mathrm{P} / 2)$ placed symmetrically about the beam centerline, the maximum deflection $\Delta$ computed at the beam centerline is expressed as

$$
\Delta=\frac{P x}{24 E_{c} I_{e}}\left(3 L^{2}-4 x^{2}\right)
$$

where $\mathrm{x}$ is the distance between the support and the point where the load is applied, $P$ is the applied load, and $E_{c}$ is the modulus of elasticity of the concrete.

We estimate the deflection of concrete members reinforced with FRP bars using the guidelines provided by the ACI Committee 440.1R-06 for the design and construction of concrete reinforced with FRP bars. According to these guidelines, the instantaneous deflection under service loads is obtained using an effective moment of inertia, $I_{e}$, given by

$$
I_{e}=\left(\frac{M_{c r}}{M_{a}}\right)^{3} \beta_{d} I_{g}+\left[1.0-\left(\frac{M_{c r}}{M_{a}}\right)^{3}\right] I_{c r} \leq I_{g}
$$

where $M_{a}$ is the applied moment, $I_{g}$ is the moment of inertia of the gross section of the beam $\left(\mathrm{mm}^{4}\right)$, and $\beta_{d}$ is the reduction coefficient.

$$
\beta_{d}=\alpha\left(1+\frac{E_{f}}{E_{s}}\right)
$$

where $E_{f}$ is the modulus of elasticity of the FRP reinforcement, $E_{s}$ is the modulus of elasticity of the reinforcing steel, and $\alpha$ is a bond-dependent coefficient, which is set as 0.5 for GFRP bars. The parameter $\beta_{d}$ takes into account bond properties and the modulus of elasticity of FRP bars. $I_{c r}$ is the moment of inertia of the cracked section $\left(\mathrm{mm}^{4}\right)$.

$$
I_{c r}=\frac{b d^{2}}{3} k^{3}+n A_{r} d^{2}(1-k)^{2}
$$

where $k=\sqrt{2 \rho n+(\rho n)^{2}}-\rho n$ is the ratio of the depth of the neutral axis to the reinforcement depth ( $\rho=A_{r} / b d$ is the reinforcement ratio), $A_{r}$ is the area of longitudinal reinforcement $\left(\mathrm{mm}^{4}\right), b$ is the beam width $(\mathrm{mm})$, and $n=E_{r} / E_{c}$ is the modular ratio of reinforcement to concrete.

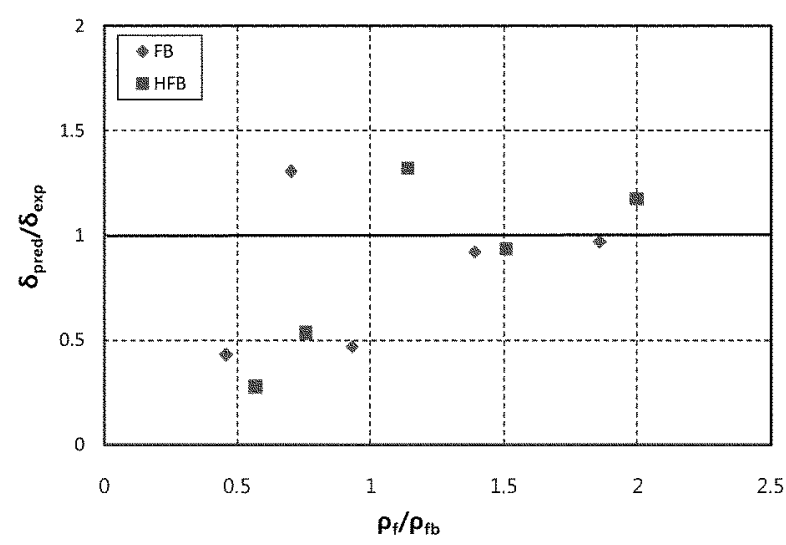

Fig.8. Comparison between Predicted and Experimental Deflection Under Service Load

Table 5. shows comparisons between the experimental results and those predicted by ACI 440.1R-06. The ACI 440 equation for the design of FRP reinforcement beams estimates that deflections 
Table 5. Comparison of Experimental and Analytical Deflection of FRP Reinforced Beams

\begin{tabular}{c|c|c|c|c|c|c|c}
\hline \multirow{2}{*}{ Specimen } & \multirow{2}{*}{} & \multicolumn{3}{|c|}{ Service load } & \multicolumn{3}{c}{ Ultimate load } \\
\cline { 3 - 8 } & & $\delta_{\text {exp }}(\mathrm{mm})$ & $\delta_{\text {pred }}(\mathrm{mm})$ & $\delta_{\text {pred }} / \delta_{\text {exp }}$ & $\delta_{\text {exp }}(\mathrm{mm})$ & $\delta_{\text {pred }}(\mathrm{mm})$ & $\delta_{\text {pred }} / \delta_{\text {exp }}$ \\
\hline FB-2 & 0.46 & 0.7 & 0.3 & 0.42 & 40.00 & 22.96 & 0.57 \\
\hline FB-3 & 0.70 & 1.61 & 2.1 & 1.30 & 46.21 & 35.54 & 0.76 \\
\hline FB-4 & 0.93 & 6.71 & 3.13 & 0.46 & 57.91 & 44.02 & 0.76 \\
\hline FB-6 & 1.39 & 7.68 & 7.07 & 0.92 & 51.68 & 46.70 & 0.90 \\
\hline FB-8 & 1.86 & 10.96 & 10.63 & 0.97 & 62.98 & 45.32 & 0.71 \\
\hline HFB-3 & 0.57 & 5.14 & 1.41 & 0.27 & 40.15 & 31.78 & 0.79 \\
\hline HFB-4 & 0.76 & 7.25 & 3.86 & 0.53 & 45.17 & 50.41 & 1.16 \\
\hline HFB-6 & 1.14 & 9.15 & 12.06 & 1.31 & 54.15 & 64.15 & 1.18 \\
\hline HFB-8 & 1.51 & 12.73 & 11.86 & 0.93 & 56.77 & 55.60 & 0.97 \\
\hline HFB-10 & 2.00 & 9.04 & 10.58 & 1.17 & 42.97 & 45.92 & 1.06 \\
\hline Mean & & - & - & 0.83 & - & - & 0.89 \\
\hline $\begin{array}{l}\text { Standard } \\
\text { deviation }\end{array}$ & & - & - & 0.38 & - & & - \\
\hline
\end{tabular}

in the tested members are smaller than the measured deflections. However, Fig. 8. shows that the experimental deflections of over-reinforced beams compare well with those predicted by ACI 440.1R-06 at the service load level.

\subsection{Strain Distribution}

Fig.9. shows the typical behavior of concrete and reinforcement strains. Both strains remain fundamentally linear. The increase in the FRP reinforcement ratio decreases the strains measured in both bars and concrete.

The load-strain curves exhibit two stages of behavior

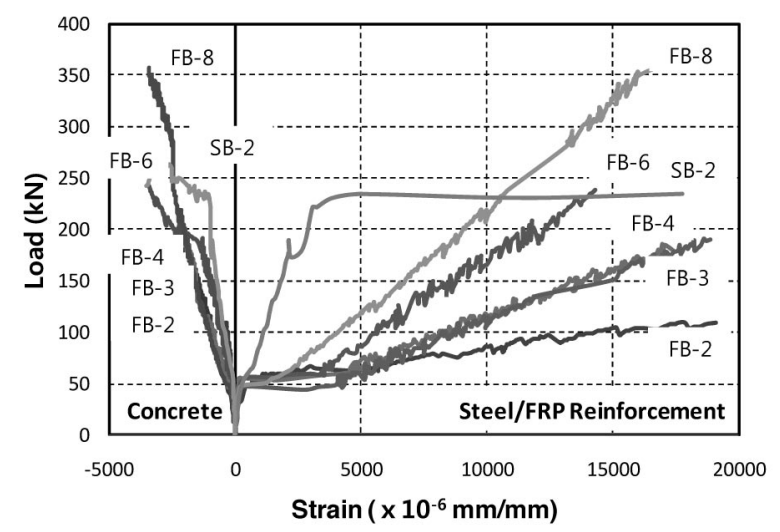

(a) SB and FB Beams $\left(f_{c}^{\prime}=30 \mathrm{MPa}\right)$

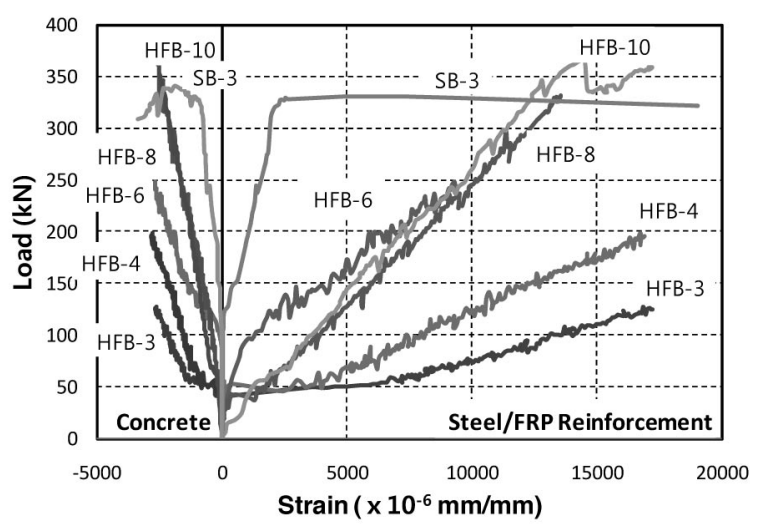

(b) HSB and HFB Beams $\left(f_{c}^{\prime}=50 \mathrm{MPa}\right)$

Fig.9. Strain Variation in Concrete and Reinforcement of Beams similar to those in the load-deflection curves. All beams exhibit a linear behavior in the uncracked stage; both the compressive strain in the concrete and the tension strain in the GFRP bars increase at nearly the same rate. As the applied load increases in the cracked stage, the tension strain of the GFRP bars increases at a faster than the compressive strain of the concrete because the neutral axis shifts upwards.

For the over-reinforced beams, concrete crushing occurred at strain levels in excess of ACI assumes 0.003 . For these three beams (FB-6, FB-8, and HFB-6), the maximum compressive strains in concrete are between $0.004 \sim 0.0045,33 \%$ higher than the ACI assumed value of 0.003 .

The strain distribution in the concrete and FRP bars is proportional to the distance from the neutral axis in all beams. The calculated elastic neutral axis for the section correlates well with the neutral axis determined from the measured strains.

\subsection{Deformability}

For steel-reinforced concrete, ductility is quantified by the ratio of displacement or curvature values at ultimate failure and at yielding. These definitions depend primarily on the distinct yielding level and post-yielding plateau of steel bars.

The conventional definition of ductility in FRPreinforced concrete beams is misleading due to the linear stress-strain relation of FRP bars that exists until failure. Therefore, deformability is introduced as a means to assess the displacement of the curvature that occurs before the rupture of reinforcement. ISIS Canada (The Canadian network of Centers of Excellence on Intelligent Sensing for Innovative Structures) (2001) define the deformability of sections reinforced with FRP as the ratio of the product of the moment and curvature that correspond to a maximum compressive strain of 0.001 . The ISIS Canada requires a performance factor greater than 4 or 6 for rectangular and $\mathrm{T}$-sections respectively. In this study, we measure deformability by

Deformability $=$ Moment factor $\times$ Deflection factor 
where

$$
\begin{aligned}
\text { Moment Factor } & =\frac{\text { Moment at ultimate }}{\text { Moment at Concrete Compressive Strain of } 0.001} \\
\text { Deflection Factor } & =\frac{\text { Deflection at ultimate }}{\text { Deflection at Concrete Compressive Strain of } 0.001}
\end{aligned}
$$

As shown in Table 6., a permissible value of deformability factor greater than or equal to 4 is adopted for all GFRP reinforced beams. Although the concrete compressive failure mode is more ductile than FRP rupture, Fig.10. shows that beams with underreinforced GFRP bars (which fail by tensile rupture) have larger deformability factors than those with overreinforced GFRP bars, which fail because of concrete compression.

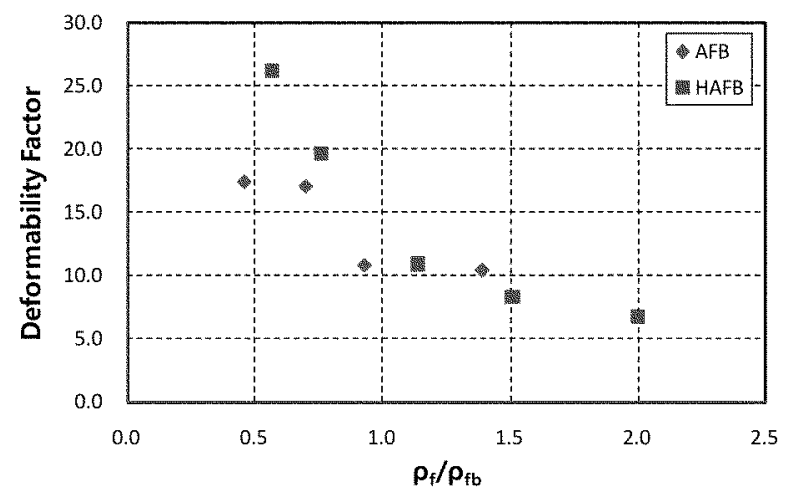

Fig.10. Deformability Factor of Beams

Table 6. Deformability Factors (DFs) for FRP Reinforced Beams

\begin{tabular}{ccccc}
\hline & $\rho_{\mathrm{f}} / \rho_{\mathrm{fb}}$ & $\begin{array}{c}\text { Moment } \\
\text { Factor }\end{array}$ & $\begin{array}{c}\text { Deflection } \\
\text { Factor }\end{array}$ & $\begin{array}{c}\text { Deformability } \\
\text { Factor }\end{array}$ \\
\hline FB-2 & 0.46 & - & - & - \\
FB-3 & 0.70 & 2.22 & 7.83 & 17.42 \\
FB-4 & 0.93 & 2.27 & 7.52 & 17.06 \\
FB-6 & 1.39 & 1.76 & 6.11 & $\mathrm{~s} 10.75$ \\
FB-8 & 1.86 & 2.05 & 5.07 & 10.37 \\
HFB-3 & 0.57 & 2.45 & 10.66 & 26.12 \\
HFB-4 & 0.76 & 2.79 & 7.03 & 19.60 \\
HFB-6 & 1.14 & 3.08 & 3.55 & 10.91 \\
HFB-8 & 1.51 & 3.17 & 2.61 & 8.27 \\
HFB-10 & 2.00 & 2.18 & 3.11 & 6.77 \\
\hline
\end{tabular}

\section{Conclusions}

Twelve concrete beams reinforced with steel and FRP bars are tested under static loading conditions. The behavior of the beams is monitored to measure crack widths, crack spacing, mid-span deflections, and strains. The results obtained in this investigation yield the following conclusions.

The behavior of beams reinforced with GFRP bars is bilinearly elastic until failure. The stiffness of beams reinforced with GFRP bars is further reduced after the initiation of cracks than it is in beams reinforced with steel bars. In addition, the deflections and strains in beams reinforced with GFRP bars are generally larger than those in beams reinforced with steel bars. This is due to the low modulus of elasticity and the different bond characteristics of the GFRP rebars. To ensure adequate flexural stiffness for deflection, the flexural design of FRP reinforced concrete beams requires over-reinforcement.

Deflection in concrete beams reinforced with GFRP bars can be accurately predicted using the ACI 440.1R-06 equations. The experimental data obtained in this investigation compare well with those predicted by the ACI 440.1R-06 equations.

As the concrete strength and the reinforcement ratio increase, the flexural capacities of the tested beams increase, but the increase is limited by the concrete compressive failure strain of over-reinforced concrete beams. Although an ultimate concrete strain of $\varepsilon_{c u}=$ 0.003 is assumed according to ACI, it is shown that higher ultimate strains should be applied for beams to predict the ultimate load.

The crack width is independent of the concrete strength and decreases as the reinforcement ratio increases.

\section{Acknowledgments}

This work is supported by the Sustainable Building Research Center of Hanyang University, which is supported by the SRC/ERC program of MOST (R11-2005-056-01003-0) and the Korea Research Grant funded by the Korean Government (KRF-2006511-D00405).

\section{References}

1) ACI Committee 440 (2006). ACI 440.1R-06 Design and Construction of Concrete Reinforced with FRP Bars, American Concrete Institute, 2006.

2) Benmokrane B., Chaallal O. and Masmoudi R. (1996) Flexural Response of Concrete Beams Reinforced with FRP reinforcing Bars, ACI Structural Journal, 93(1), pp.46-55.

3) Burong Zhang (2004) Radhouane Masmoudi, Brahim Benmokrane. Behavior of one-way concrete slabs reinforced with CFRP grid reinforcements, Construction and Building Materials, 18, pp.625-635.

4) Hayder A. Rasheed, Rim Nayal, Hani Melhem (2003) Response prediction of concrete beams reinforced with FRP bars. Composite Structures, 65, pp.193-204.

5) H. A. Abdalla (2002) Evaluation of deflection in concrete members reinforced with fiber reinforced polymer (FRP) bars. Composite Structures, 56, pp.63-71.

6) Houssam Toutanji, Yong Deng (2002) Deflection and Crack-width prediction of concrete beams reinforced with glass FRP rods. Construction and Building Materials, 17, pp.69-74.

7) Houssam A. Toutanji, Mohamed Saafi (2000) Flexural Behavior of Concrete Beams Reinforced with Glass Fiber Reinforced Polymer(GFRP) Bars, ACI Structural Journal, 97(5), pp.712-719.

8) ISIS Canada (2001) Reinforcing Concrete Structures with Fiber Reinforced Polymers, The Canadian network of Centres of Excellence on Intelligent Sensing for Innovative Structures, ISIS-M03-01.

9) John Netwhook, Amin Ghali, and Gamil Tadros (2002), Cracking and Deformability of Concrete Flexural Sections with Fiber Reinforced Polymer, Journal of Structural Engineering, 128(9), Sep., pp.1195-1201. 
10) Korea Institute of Construction Technology (KICT). (2004) Design and construction technology for concrete structures using advanced composite materials: FRP rebars and grids (in Korean). Interim report submitted to the Korea Research Council of Public Science and Technology.

11) Michele Theriault and Brahim Benmokrane (1998), Effects of FRP Reinforcement Ratio and Concrete Strength on Flexural Behavior of Concrete Beams, Journal of Composites for Construction, 2(1), Feb. pp.7-16.

12) Radhouane Masmoudi, Michele Theriault and Brahim Benmokran (1998) Flexural Behavior of Concrete Beams Reinforced with Deformed Fiber Reinforced Plastic Reinforcing Rods, ACI Structural Journal, 95(6), pp.665-676. 